\title{
Visualising the COVID-19 related disruptions to long-distance population mobility in Australia
}

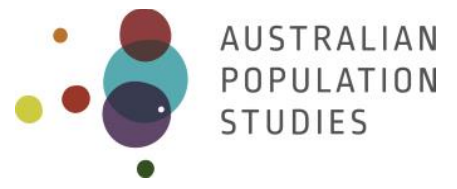

\author{
Irina Grossman* The University of Melbourne \\ Tom Wilson The University of Melbourne \\ Jonathan Garber The University of Melbourne \\ Jeromey Temple The University of Melbourne
}

*Corresponding author. Email: irina.grossman@unimelb.edu.au. Address: Melbourne School of Population and Global Health, The University of Melbourne, Melbourne, Vic 3010, Australia.

Paper received 6 March 2021; accepted 26 March 2021; published 31 May 2021

\section{Introduction}

The public health response to mitigate the spread of COVID-19 in Australia involved an entry ban limiting entrance to Australia to its citizens and residents, a travel ban preventing Australians from leaving the country, and a series of state border closures limiting travel within the country (Grattan Institute 2020). The aims of this paper are to document the extent of the downturn in domestic and international air mobility in Australia that was associated with COVID-19. We use aviation statistics as a proxy for long-distance human mobility. Several papers have already been written on COVID-19 impacted mobility using flight data (e.g., lacus et al. 2020; Garcia-Gasulla et al. 2020; Lau et al. 2020; Suzumura et al. 2020). Our contribution focuses on the Australian context, providing a summary visual representation of the huge changes in both domestic and international mobility trends which have occurred recently.

\section{Data and methods}

The Australian Government's Bureau of Infrastructure and Transport Research Economics (BITRE) provides publicly available monthly publications documenting domestic and international aviation activity (https://www.bitre.gov.au/statistics/aviation). The international data was sourced from the 'Table 5 Scheduled International Traffic by City Pairs' dataset found in the 'Table_5' sheets in the January 2019 - December 2020 Excel workbooks, published as part of the International Airline Activity-Monthly Publications (BITRE 2021a). The domestic data was sourced from the 'Australian Domestic Airlines, Traffic-On-Board-By-Stage Passengers, Top Competitive Routes' dataset found in the 'Summary' sheets in the January 2019 -December 2020 Excel workbooks published as part of the Australian Domestic Aviation Activity Monthly Publications (BITRE 2021b).

MATLAB 2020b was used to aggregate monthly data into time series datasets for total domestic and international passenger numbers. Additionally, time series data was assembled for travel between Australian capital cities. RStudio 1.3.1056 was used together with the Circlize package (Gu et al. 
2014) to illustrate the geographical connections and numbers of passengers moving between Australian capital cities. We created these for the months of December 2019, April 2020, August 2020, and December 2020. Microsoft Excel 2016 was used to create a line chart representing changes in domestic and international travel for the 2019 - 2020 period.

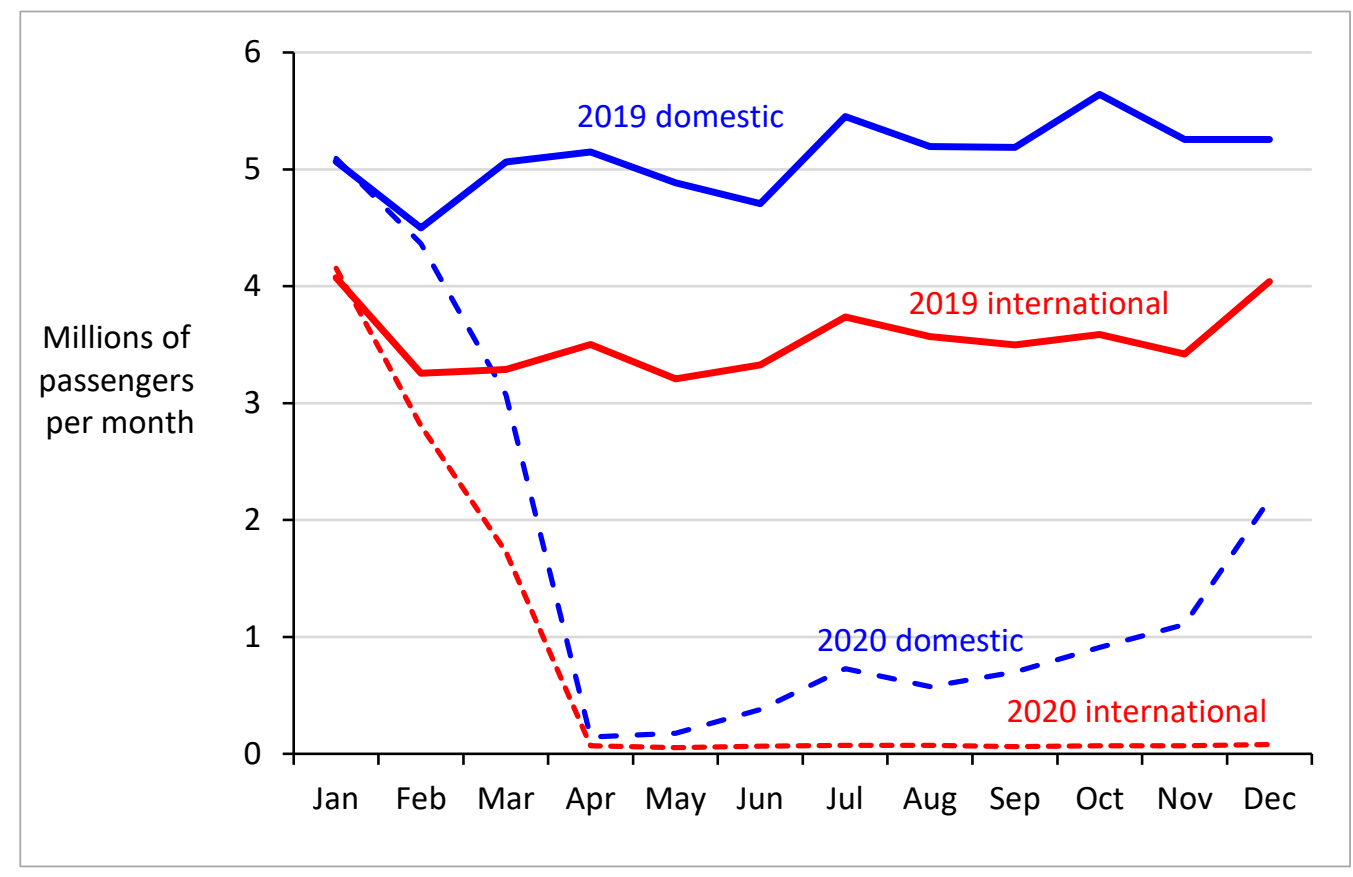

Figure 1: Australian international and domestic air passengers, by month, 2019 and 2020

Source: International data was sourced from the passenger numbers provided through the 'Table_5' sheets in the excel workbooks (BITRE 2021a). Domestic data was sourced from the 'REVENUE PASSENGERS' column in the 'Summary' sheets of the excel workbooks (BITRE 2021b).

Note: Passenger numbers include both inbound and outbound flights for international flights.

\section{Key features}

The line chart in Figure 1 shows that international and domestic travel both decreased dramatically in the first few months of 2020. In April 2020, international and domestic passenger numbers were at just 2.0\% and 2.8\% of their April 2019 numbers, respectively. This corresponds with the closure of the Australian border, the international travel ban, and state border closures (Grattan Institute 2020). International travel remained flat through till the end of 2020. Recovery in Australian aviation activity has been led by domestic travel. Domestic travel experienced a local maxima in July before decreasing again slightly, which was expected given the state border closures associated with the second wave of COVID-19 in Victoria (Grattan Institute 2020). Since September there has been a gradual increase in travel, and this rate increased significantly in December of 2020, corresponding with the opening of state borders (Grattan Institute 2020) following the successful suppression of the second wave in Victoria. By December 2020 domestic passenger numbers had recovered to $41 \%$ of the December 2019 numbers. 


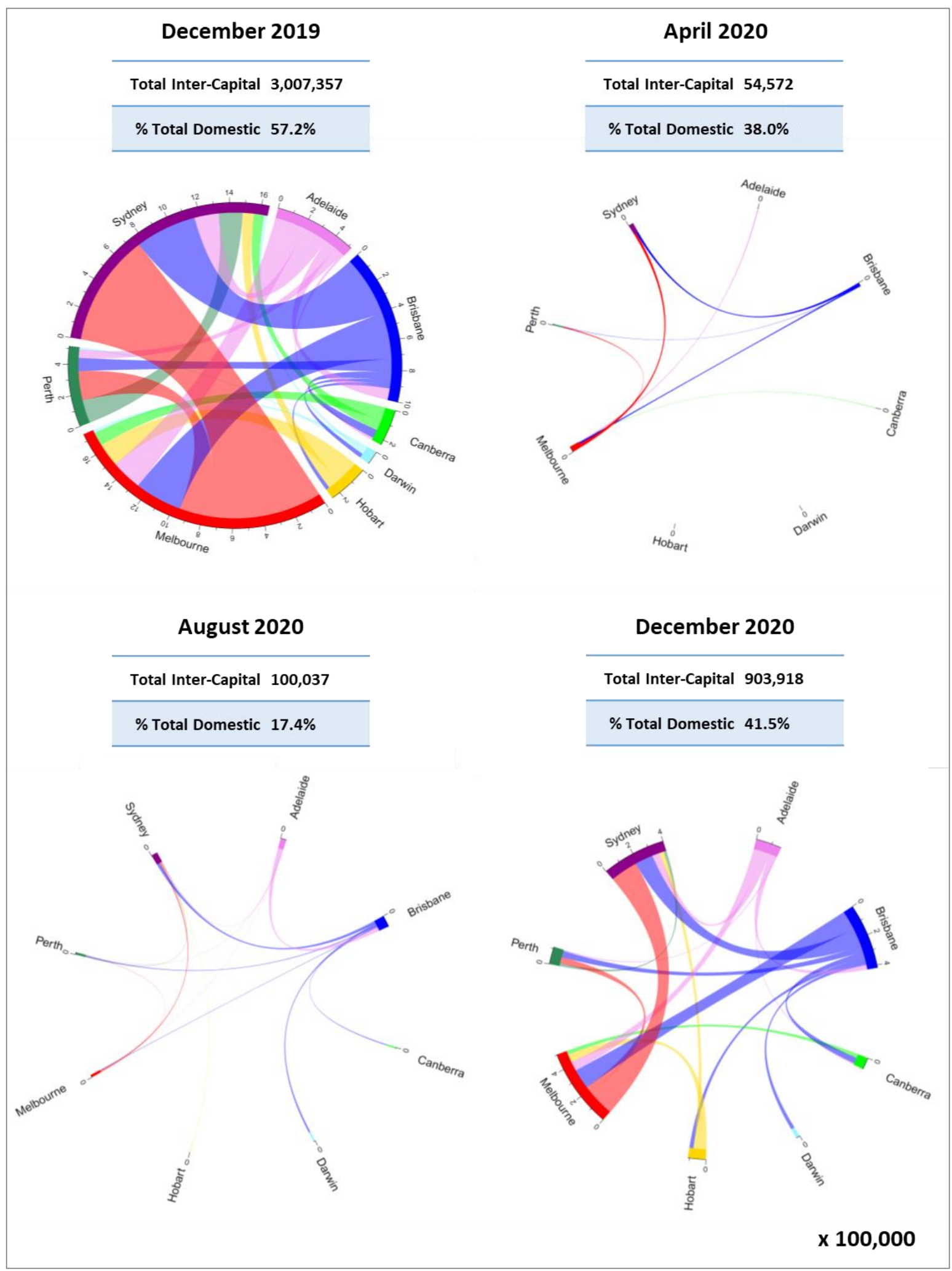

Figure 2: Circular charts comparing Inter-Capital City travel in selected months of 2019 and 2020.

Source: Inter-capital city passenger numbers were sourced from the 'REVENUE PASSENGERS' column in the 'SUmmary' sheets of the excel workbooks (BITRE 2021b).

Notes: The width of the links indicates the number of passengers travelling between two cities. These links are not directional. Each unit on the axes of the circular charts represents 100,000 passengers. Total inter-capital city passenger numbers, and inter-capital passenger numbers as a percentage of total domestic passenger numbers, are also presented. 
The circular charts in Figure 2 provide more detail on changes in domestic travel in 2020 by depicting passenger flows between capital cities. The December 2019 circular chart depicts standard preCOVID-19 passenger flows, when inter-capital city travel comprised $57 \%$ of total domestic passenger numbers. The April and August 2020 circular charts show how Australia became disconnected, with few passengers moving between the capital cities. The December 2020 circular chart displays the recovery in domestic air travel with the reforming of key inter-capital city links, particularly those between Melbourne, Sydney, and Brisbane.

\section{Ethics approval}

Ethics approval for this project was granted by the Melbourne School of Population and Global Health (MSPGH) Human Ethics Advisory Group (HEAG), ID 2056902.1.

\section{Acknowledgements}

The authors gratefully acknowledge funding support from the Melbourne School of Population and Global Health for COVID-19 research.

\section{References}

BITRE (2021a) International Airline Activity-Monthly Publications. https://www.bitre.gov.au/publications/ongoing/international airline activitymonthly publications. Accessed on 23 February 2021.

BITRE (2021b) Australian Domestic Aviation Activity Monthly Publications. https://www.bitre.gov.au/publications/ongoing/domestic airline activity-monthly publications. Accessed on 23 February 2021.

Garcia-Gasulla D, Napagao S A, Li I, Maruyama H, et al. (2020) Global Data Science Project for COVID-19 Summary Report. https://arxiv.org/abs/2006.05573. Accessed on 14 September 2020.

Grattan Institute (2020) Grattan: coronavirus announcements tracker. https://docs.google.com/spreadsheets/d/1ZanCmSueVD26Xrw1hMszi5Q aQwsZJe78Y5HCLwXQ 64/edit\#gid $=0$. Accessed on 26 February 2021.

Gu Z, Gu L, Eils R, Schlesner M, \& Brors B (2014) circlize implements and enhances circular visualization in R. Bioinformatics 30(19): 2811-2812. https://doi.org/10.1093/bioinformatics/btu393.

lacus S M, Natale F, Santamaria C, Spyratos S, \& Vespe M (2020) Estimating and projecting air passenger traffic during the COVID-19 coronavirus outbreak and its socio-economic impact. Safety Science 129: 104791. https://doi.org/10.1016/i.ssci.2020.104791.

Lau H, Khosrawipour V, Pior Kocbach P, Mikolajczyk A, Ichii H, Zacharski M, Bania J, \& Khosrawipour T (2020) The association between international and domestic air traffic and the coronavirus (COVID-19) outbreak. Journal of Microbiology, Immunology and Infection 53(3): 467-472. https://doi.org/10.1016/i.jmii.2020.03.026.2020.

Suzumura T, Kanezashi H, Dholakia M, Ishii E, Napagao S A, Prez-Arnal P, \& Garcia-Gasulla D (2020) The impact of COVID-19 on flight networks. https://arxiv.org/abs/2006.02950. Accessed on 14 September 2020. 